\title{
Job Insecurity and Unsafe Behaviour: Exploring Curvilinear and Moderated Relationships
}

\begin{abstract}
This study examines a curvilinear relationship between job insecurity and unsafe behaviour among coal miners. Drawing from conservation of resources theory, we develop and investigate an explanation for coal miners' reactions to job insecurity based on their allocation of psychological resources at different levels of job insecurity. By using three-wave longitudinal data from 209 coal miners in northern China, we find support for the U-shaped relationship between job insecurity and unsafe behaviour. That is, coal miners' unsafe behaviour gradually decreases when they perceive a level of insecurity in their jobs, but beyond a certain point, their unsafe behaviour increases. Furthermore, we find that psychological detachment, but not self-control, moderates the curvilinear relationship, such that coal miners with higher psychological detachment exhibit less unsafe behaviours. We also discuss the theoretical implications of this study on job insecurity and unsafe behaviours, and the practical implications for organisations in the coal mining industry. Keywords: coal miner; job insecurity; unsafety behaviour; self-control; psychological detachment
\end{abstract}

\section{Introduction}

Across various occupations, coal mining is one of the most hazardous (Lenné, Salmon, \& Liu, 2012), with relatively high annual fatalities compared with other industries. For example, in China, more than 1,000 deaths every year are caused by coal mining accidents (Zhang, Shi, \& Wu, 2017). Although organisations have attempted to eliminate the safety hazards of coal miners' working conditions through the provision of safe tools, facilities, and equipment, research has demonstrated that approximately $80 \%$ of the accidents result from unsafe human behaviours (e.g., Li, Lu, Hsu, 
Gray, \& Huang, 2015). Therefore, scholars have started to investigate the psychological mechanisms that influence unsafe behaviours. In particular, job insecurity, which is the perceived threat of one's future continuance of employment, has been identified as a psychological factor that significantly contributes to or motivates the unsafe behaviours of individuals (Ashford, Lee, \& Bobko, 1989). In China, a range of factors such as the lack of guaranteed lifetime employment, mass retrenchments as technology replaces human labour, economic downturns, and global competition, have collectively contributed to high levels of anxiety, distress, and fear of job loss among existing employees (Lam, Liang, Ashford, \& Lee, 2015). In addition to these factors, job insecurity is especially pronounced among coal miners due to the nature of the industry. That is, coal mining is a labour-focused occupation, and coal miners can be easily replaced by younger and stronger ones. Job insecurity is therefore regarded as a significant concern in the coal mining industry in China today.

The tension between the need for organisations to continually cut costs leading to job insecurity among employees on the one hand, and the need for even job-insecure workers to comply with safe behaviours (which may possibly hinder their performance) on the other hand, poses a critical question: what is the relationship between job insecurity and unsafe behaviour? The dominant opinion in the literature is that, when facing the potential loss of employment, employees tend to focus on productivity at the expense of safety, because unsafe behaviours can save substantial personal resources (e.g., energy and attention) for them to perform work tasks more effectively and efficiently, and they may believe that high performance is central to keeping their jobs (e.g., Probst, 2004; Shoss, 2017; Slappendel, Laird, Kawachi, Marshall, \& Cryer, 1993). Many studies have shown that individuals who perceived their jobs to be insecure are likely to engage in 
violations of safety policies, as their motivation to comply with safety standards decrease (Probst, Petitta, Barbaranelli, Lavaysse, 2018; Probst, 2004).

Conversely, Parker, Axtell, and Turner (2001) found that job insecurity is positively related to safety-related outcomes, and Prost (2004) suggested that job insecurity can have less of a negative impact on employee safety outcomes if an organisation has a healthy safety climate. Furthermore, Brockner, Grover, Reed, and Dewitt (1992) suggested that low levels of job insecurity create work complacency, which is identified as the worst enemy of safety behaviours (Hyten \& Ludwig, 2017). Therefore, we contend that an acquisitive pursuit of low levels of job insecurity may be too much of a good thing.

Accordingly, we propose that the two contradictory opinions discussed signify the potential presence of curvilinear effects and moderators (e.g., Lam, et al., 2015; Le, et al., 2010) in the relationship between job insecurity and unsafe behaviours. Specifically, we employ conservation of resources theory (COR theory; Hobfoll, 1989) to help interpret the exhibition of the two inconsistent findings by suggesting a novel and curvilinear relationship between job insecurity and unsafe behaviours. In order to further understand the nature of the relationship, it is necessary to expand our framework by investigating potential moderators of the curvilinear effect. In this study, we introduce two psychological conditions: self-control (i.e., a psychological process inhibiting or regulating individuals' impulses, emotions, or automatic behaviours), and psychological detachment (i.e., a psychological tendency mentally disengaging oneself from work). In doing so, we contribute to a more thorough understanding of the curvilinear relationship between job insecurity and unsafe behaviours, and the psychological mechanisms underlying such a relationship, since moderation analysis is critical for understanding the generalisability of research findings to people with different psychological characteristics. Therefore, verifying the nature of 
the curvilinear relationship and its moderation effects has both theoretical and practical implications, which can shed light on the process through which job insecurity influences employees' safety-related behaviours, and provide guidance for curbing their unsafe behaviours in the workplace.

\section{The Relationship Between Job Insecurity and Unsafe Behaviour}

The central tenet of COR theory is that individuals are motivated to take actions to protect their existing resources and acquire new resources (Hobfoll, 1989; Hobfoll, Halbesleben, Neveu \& Westman, 2018). Resources refer to "anything perceived by the individual to help attain his or her goals" (Halbesleben, Neveu, Paustian-Underdahl, \& Westman, 2014, p1337), such as objects (e.g., housing), personal characteristics (e.g., optimism), or conditions (e.g., seniority). At the heart of most definitions, job insecurity, regarded as a stressor (Sverke, De Witte, Näswall, \& Hellgren, 2010), can impair employees' sense of perceived control (i.e., a type of resource), and potentially threaten their employment (i.e., a type of resource) which would hinder them from pursuing life happiness and career success (i.e., personal goals) (Ashford et al., 1989; Lam et al., 2015). When their resources are threatened, individuals will be bound to take actions "to protect themselves from losing resources, or to recover from resource loss" (Halbesleben et al., 2014, p. 1337). Such actions may include critical organisational outcomes. For example, the more insecure employees feel about their jobs, the higher the intention to quit as they seek more secure career opportunities (e.g., Ashford et al., 1989). The more dissatisfied employees are with their perceived job security, the lower their organisational commitment (Ashford et al., 1989), since job insecurity breaches the psychological contract between the employees and their workplace (i.e., a type of personal resource; Kiazad, Seibert, \& Kraimer, 2014). This then arouses their defensive mode to protect themselves by conducting certain aggressive or irrational behaviours (Hobfoll, et al., 2018). 
Overall, past research has found that, when employees perceive that their jobs are under threat, they feel stressed and dissatisfied. The stress and dissatisfaction can lead to lowered safety-related behaviours (Probst, 2001).

When applied to the safety-related outcomes at work, COR theory can also provide some insights as to why job insecurity can induce unsafe behaviours in the context of the current research. For coal miners in China, the perceived threat of job insecurity becomes more imminent and intense (Lam, Liang, Ashford, \& Lee, 2015), since their low levels of education and lack of transferable skills make it difficult for them to find alternative jobs in other industries ( $\mathrm{Yu}, \mathrm{Cao}$, Xie, Qu \& Zhou, 2019). Therefore, coal miners are especially anxious about maintaining their employment (Masia \& Pienaar, 2011). An added complexity is that the demands of production and safety are not valued equally by employees (Janssens, Brett, \& Smith, 1995; Jiang \& Probst, 2015). When a task involving risk demands that employees be highly productive, a dilemma arises: does one forego safety compliance in order to maximise productivity or does one compromise on optimum productivity in order to adhere to safety practices? (Byrd, Gailey, Probst, \& Jiang, 2018). This dilemma is especially salient in the coal mining industry due to its high emphasis on production and performance (Paul \& Maiti, 2007). The more an organisation emphasizes production and performance, the more employees perceive that production and performance should be prioritised over safety (Janssens et al., 1995). Therefore, coal miners with high levels of job insecurity are more inclined to devote their resources toward meeting production schedules rather than safety compliance (Probst \& Brubaker, 2007).

In addition, research from other disciplines similarly suggest that, for individuals who perceive a strong sense of job insecurity, unsafe behaviour is a plausible choice to maintain their employment. The prospect theory of behavioural economics argues that an individual's risk 
preference is not consistent (Fiegenbaum \& Thomas, 1988). That is, people tend to engage in risky activities to gain opportunistic benefits in a loss situation. Job insecurity is a sign of the threat to financial stability and family well-being (De Witte, 1999). Under such circumstances, employees calculate the ratio of organisational rewards to personal input, and thereafter pursue a higher ratio (Costa \& Neves, 2017). Unsafe behaviours have the potential to increase one's working pace and personal comfort without involving resource consumption, whereas safe behaviours may require more time, physical strength, or other costs to coal miners (Probst, 2001). Therefore, unsafe behaviour may be perceived as a way to generate a relatively higher ratio of reward to input than safe behaviour. In fact, previous longitudinal studies (Jiang \& Probst, 2015;), controlled laboratory experiments (Probst, 2002), and a meta-study (Christian, Bradley, Wallace, \& Burke, 2009) collectively support the notion that job insecurity has a positive relationship with unsafe behaviour.

However, we contend that the above positive relationship between job insecurity and unsafe behaviour only happens when job insecurity levels fall within the moderate to high level range. When job insecurity levels are low to moderate, the relationship differs. According to COR theory, personal resources are finite, and people have to allocate them reasonably in order to fit with their environment (Hobfoll, 1989). Kaplan and Gangestad (2005) propose that, when individuals strive to achieve their goals, poor allocation of resources is as severe as an outright loss of resources. In other words, a person with abundant resources will not necessarily thrive, but the person who is best able to allocate his/her available resources appropriately (Halbesleben et al., 2014; Hobfoll, 1989; Kaplan \& Gangestad, 2005). The majority of earlier research on the relationship between job insecurity and safety-related outcomes tend to assume that people's allocation of resources is rational. Such an assumption is problematic, as research has shown that people always engage in irrational behaviours (Denes-Raj \& Epstein, 1994). Given that one's allocation of resources is not 
always rational, it follows that the relationship between job insecurity and unsafe behaviours is not always positive.

When employees have a low sense of job insecurity, they perceive themselves to have a high degree of control and are confident that their abilities will keep their positions secure in their organisations (Brockner et al., 1992). Under such circumstances, complacency may set in (Brockner et al., 1992) and is a plausible reaction for the subjects of our study, coal miners. Mining is an occupation that requires workers to spend most of their day underground, performing repetitive and tedious tasks, which creates a likelihood that they "withdraw attentional effort from the task and approach their assignment in a thoughtless, routinized manner" (Warm, Matthews, \& Finomore Jr., 2018, p.117). In their complacency, coal miners may unconsciously invest minimal resources to safety awareness (Moray \& Inagakit, 2010), resulting in ignorance of safety procedures which puts themselves at risk. Previous studies have demonstrated that complacency is a silent killer, and it can lead to serious human-made accidents (e.g., Årstad \&Aven, 2017; Moray \& Inagakit, 2010).

When employees' sense of job insecurity gradually increases to moderate levels, complacency levels may diminish (Brockner et al., 1992), and more cognitive resources may be channelled into monitoring behaviours. For example, coal miners may be more inclined to self-reflect on their practices, which would be less likely to occur when job insecurity levels are low, and question whether, for example, a near-miss was caused by taking short cuts. Coal miners may be more inclined to allocate their cognitive resources toward self-scrutiny if they recognise that violations of safety regulations or poor accident records expose them to a greater risk of being fired (Parker, Axtell, \& Turner, 2001). Therefore, we expect that when job insecurity moves from low to moderate levels, the unsafe behaviours of employees decrease in frequency. 
Taken together, we propose that the tension between productivity and safety, and the irrational allocation of psychological resources, govern how job insecurity affects unsafe behaviour. When coal miners feel secure about their job, they unconsciously engage in unsafe behaviours because their complacency leads to a poor allocation of their resources. As job insecurity increases from low to moderate levels, coal miners will allocate more available resources to safety awareness and intentionally reduce their unsafe behaviours. When job insecurity intensifies from moderate to high levels, the competing demands of productivity and safety would motivate coal miners to devote more resources to productivity than to safety compliance in order to regain control over their employment. Hence, we posit the following curvilinear hypothesis:

Hypothesis 1: The relationship between job insecurity and unsafe behaviour is U-shaped.

\section{The Moderating Role of Self-control and Psychological Detachment}

Previous studies have demonstrated that psychological characteristics can influence the fluctuation and allocation of conserved personal resources (Halbesleben, et al., 2014; Kuhnel, Sonnentag, \& Bledow, 2012). In other words, some employees can more effectively recover, or more efficiently allocate personal resources, which may alter resource-sensitive behaviours, such as unsafe behaviour. Therefore, we expect that our proposed U-shaped relationship between job insecurity and unsafe behaviours may be moderated by two psychological characteristics, self-control and psychological detachment, both of which can play a role in changing and allocating individuals' personal resources (Rivkin, Diestel, \& Schmidt, 2014; Zijlstra, Cropley, \& Rydsted, 2014).

\subsection{Psychological detachment}

Psychological detachment refers to "the individual's sense of being away from work situation" (Etzion, Eden, \& Lapidot, 1998, p. 579). Psychological detachment is an experience of mental disengagement from work (Sonnentag \& Bayer, 2005), which helps individuals refrain from work- 
related duties, thoughts, and worries during their off-work time (Sonnentag \& Binnewies, 2013, p4755). Psychological detachment from one's job demands provides the opportunity to take time out and to replenish one's resources, which is beneficial for individuals to recover from work strain (Sonnentag, Binnewies, \& Mojza, 2010; Rivkin, Diestel, \& Schmidt, 2014;). Furthermore, the research also shows that employees who have a high level of psychological detachment exhibit more proactive work behaviour, which helps them to address problems at work and come up with solutions (Binnewies, Sonnentag, \& Mojza, 2010). In the context of coal miners, we speculate that psychological detachment may act as a moderator, buffering the curvilinear relationship between job insecurity and unsafe behaviour.

Earlier, we argued that as job insecurity increases from low to moderate levels, any sense of complacency among the coal miners starts to decrease, prompting a reduction in unsafe behaviours. We suggest that psychological detachment can moderate the negative relationship between job insecurity and unsafe behaviour, in that coal miners with high psychological detachment will display less unsafe behaviours than miners with low psychological detachment. This is because the ability to detach from one's job allows one to focus on other aspects of one's life, which enhances opportunities for one to replenish one's psychological resources and to acquire new ideas and perspectives, the sum of which helps one to maintain a positive view of one's work (Ruderman, Ohlott, Panzer, \& King, 2002), and to feel sufficiently energised to tackle work problems (Binnewies, Sonnentag, \& Mojza, 2010). In contrast, coal miners with low levels of psychological detachment struggle to disconnect from work issues when they are away from work (Sonnentag \& Fritz, 2015). Without a mental break from work, their work problems appear relentless, even insurmountable, and such coal miners subsequently maintain their behavioural patterns because any efforts to inspire change are perceived to be in vain. 
We suggest that coal miners, if experiencing moderate to high levels of job insecurity, will concentrate their limited resources on enhancing their productivity rather than on complying with safe work practices. Once again, we expect that psychological detachment will moderate the positive relationship between job insecurity and unsafe behaviour, in that miners with high psychological detachment will reduce their unsafe behaviours more than miners with low psychological detachment. As previously discussed, moderate to high levels of job insecurity bring about an increase in one's sense of helplessness (Brockner et al., 1992), and conversely, a reduction in one's personal resources, particularly, perceived control (Lam et al., 2015). COR theory holds that as individuals feel their circumstances deteriorating, resource gain becomes more important (Hobfoll, Halbesleben, Neveu, \& Westman, 2018). Whereas coal miners with high psychological detachment can find ways to replenish their psychological reserves when they disconnect from work, miners with low psychological detachment are continually consumed by work worries, which drains the energy reserves that could have been used toward engaging in safe work practices (Sonnentag \& Kühnel, 2016). This explains why employees with low psychological detachment tend to report high levels of fatigue, sleep complaints, and emotional exhaustion (Sonnentag, Binnewies, \& Mojza, 2010), and why they have a greater likelihood of experiencing work-related accidents or injuries (Christian et al., 2009). Given this, we posit the following:

Hypothesis 2: Psychological detachment moderates the U-curve relationship between job insecurity and unsafe behaviours.

\subsection{Self-control}

Self-control refers to one's capacity or skills to inhibit or resist impulses, temptations, habits, and to delay gratification (Van Horn, 1995; Hagger, 2010). According to the strength model of selfcontrol, self-control is characterized as (a) an individual's capacity to resist impulses so as to 
achieve long-term aims (Gino, Schweitzer, Mead, \& Ariely, 2011); (b) a tendency to follow a rule or to delay gratification (Shallice \& Burgess, 1993); and (c) a critical factor that determines the extent to which individuals engage in self-regulatory behaviours (Muraven, Tice, \& Baumeister, 1998). For example, if one has a habit of smoking after dinner, the exertion of self-control will help him/her to alter this habit, but if that person has low levels of self-control, the habitual impulse to smoke after dinner will override any resolve to quit (Muraven, Shmueli, \& Burkley, 2006). Previously, we argued that when job insecurity increases from low to moderate levels, coal miners would reduce unsafe behaviours as their complacency decreases. In turn, they would allocate more personal resources to vigilance over potential safety issues, a shift that may be especially prominent among those with higher self-control. Previous studies have demonstrated that selfcontrol primarily involves a deliberate change in one's usual responses to external events in order to maximize the adaptive outcomes at hand (Foster, Young, \& Bärnighausen, 2014). Although coal miners, by cutting corners, might improve their productivity quickly in the short term, individuals with high self-control are more inclined to resist this temptation in their recognition that unsafe behaviours may lead to high costs in the long term, such as losing one's job or even one's life (De Ridder, Lensvelt-Mulders, Finkenauer, Stok, \& Baumeister, 2012); Gino, Schweitzer, Mead, \& Ariely, 2011; Shoss, 2017). Therefore, when one's sense of job insecurity changes from low to moderate levels, employees with higher degrees of self-control are more likely to allocate their personal resources toward safety compliance in a bid to keep their employment secure. In contrast, coal miners with lower levels of self-control lack of ability being cognizant of complacency, and are not able to allocate more resources to vigilance, which may result in more unsafe behaviours. 
We also argue that coal miners will exhibit more unsafe behaviours when their levels of job insecurity shift from moderate to high degrees, and that such a positive relationship is more pronounced among coal miners with higher self-control than those with lower self-control. We contend that personal resources continually decrease as job insecurity levels escalate, given that job insecurity is a prolonged uncertainty with a detrimental impact that compounds over time (Burgard, Brand, \& House, 2009; Shoss, 2017). As one becomes increasingly fearful for their job, one's sense of helplessness intensifies (Brockner et al., 1992), depleting one's personal resources such as perceived control (Lam et al., 2015). The more resources are depleted, the more difficult it becomes to exert self-control (Hagger \& Martin, 2015). COR theory suggests that if there is no resource gain after resource investment, individuals who are already stretched may exhaust their depleted resources to the point where their capacity for self-control is undermined.

Accordingly, we argue that when job insecurity ranges between moderate to high levels, coal miners with high self-control will be more susceptible to resource depletion, since the exertion of self-control is demanding of one's personal resources. That is, miners with high self-control are pushed to a point where they feel they can no longer afford to invest what remaining resources they have into safety considerations. By contrast, miners with lower self-control succumb to the temptation of gaining immediate productivity (Chi, Chang, \& Huang, 2015; De Ridder et al., 2012) and are not concerned with safety regulations all the time. Therefore, we expect that low selfcontrol coal miners may not regulate their existing unsafe behaviours. Overall, we expect that miners with high self-control will exhibit more unsafe behaviours than their counterparts with lower self-control. We therefore hypothesize the following:

Hypothesis 3: Self-control moderates the U-curve relationship between job insecurity and unsafe behaviour. 
[Insert Figure 1 about here]

\section{Methods}

\subsection{Participants and procedures}

We collected data by conducting a survey of coal miners in several state-owned coal companies located in the north of China. The coal miners were all male with low levels of education and primarily came from poverty-stricken areas. At the time of data collection, the coal companies were undertaking a restructuring process by updating their production line and restructuring the positions and jobs of employees. Before carrying out the survey, we received approval from the senior management of the coal companies. The criteria for selecting participants were (1) permanent employees; (2) engaging in basic production work at the front line; and (3) scheduling a two-day break next month.

Three sets of questionnaires were developed and administered at three time points. At Time 1 (T1), coal miners completed a questionnaire which captured their demographic information, levels of job insecurity, and the dates of their impending two-day break. Four hundred and fifty-six miners participated in the T1 survey (a response rate of $86.40 \%$ ), and 394 valid questionnaires were obtained after incomplete questionnaires and outliers were discarded. After the participants came back to work in a second month (T2), we distributed the self-control and psychological detachment questionnaires to the same participants. We received 300 valid questionnaires (a response rate of $76.14 \%$ ). A month after the $\mathrm{T} 2$ questionnaires were issued, at the regular monthly staff meeting (T3), we distributed the unsafe behaviour questionnaire to the same participants. We obtained 209 valid questionnaires (a response rate of 69.67\%). The 209 participants had an average age of $26.7(S D=3.90)$, and an average organisational tenure of 6.71 years $(S D=4.02)$. 
Approximately half of the respondents (50.2\%) reported that they had less than five years' work experience $(N=105)$. More than half were married $(51.7 \%)$, and most of them $(83.7 \%)$ had a monthly salary of CNY 3001 - 5000 (approximately USD 435 - 725). Only 25.3\% had a college diploma or a higher qualification $(N=53)$. As an incentive, participants received CNY 10 (approximately USD 1.44) for completing each survey and received an additional CNY 30 (approximately USD 4.33) for completing all three surveys. Before the surveys began, participants were assured of anonymity and confidentiality.

The self-report approach adopted in this study has the potential to generate common method bias (CMB) and inflate analysis results. To reduce the likelihood of CMB in this study, we took several steps prior to testing the hypotheses, following the suggestions of Coway and Lance (2010). First, we researched the literature to determine the appropriateness of using self-report for our study variables. Previous research shows that this approach is appropriate for tapping into an individual's psychological and cognitive experiences (such as job insecurity, self-control, and psychological detachment) (e.g., Abildgaard, Nielsen, \& Sverke, 2017; Richter \& Näswall, 2018), and private events (such as unsafe behaviour) (Chan, 2009). Additionally, some empirical studies show that job insecurity (e.g., Byrd et al., 2016; Probst, Brubaker, \& Barsotti, 2008) and safetyrelated behaviours (Byrd et al., 2016) are best captured by self-report survey data. Second, as detailed in the following sections, we confirmed decent construct validity of the measures we used, such as acceptable reliability ranges and factor structures. Third, we actively considered CMB in the design of this study. We introduced a time lag between distributing the measures of the predictor, moderators, and criterion variables, and we ensured the anonymity of respondents (Podsakoff, MacKenzie, Lee, \& Podsakoff, 2003). Therefore, we contend that the risk of CMB has been minimized in this study. 


\subsection{Measures}

All English-language items in the questionnaire were translated into Chinese using the translation/back-translation procedure to minimize translation error. A Likert-type scale was used for the response options on all the items, where $1=$ strongly disagree to $5=$ strongly agree.

\subsubsection{Job insecurity}

Job insecurity was assessed by the 7-item and two-dimensional Job Insecurity Scale (Hellgren, Sverke \& Isaksson, 1999) at T1. The two-dimensional construct includes: (a) 3 items for quantitative job insecurity (e.g., fears of losing one's present job); and (b) 4 items for qualitative job insecurity (e.g., threats of deteriorating employment conditions). Example items of "I am worried about having to leave my job before I would like to" and "I feel uneasy about losing my job shortly" represent quantitative and qualitative job insecurity respectively. We performed a second-order confirmatory factor analysis (CFA) to test whether the two-factor model plus an overall second-order factor fit the data. The results suggested that the data fit this second-order model reasonably well $\left(\chi^{2}=25.89, \mathrm{df}=11, \mathrm{RMSEA}=0.08, \mathrm{CFI}=0.97, \mathrm{TLI}=0.95, \mathrm{SRMR}=0.03\right)$. The Cronbach's alpha for the overall scale was 0.85 .

\subsubsection{Self-control}

Self-control was assessed by the 13-item Brief Self-Control Scale from Tangney, Baumeister, and Boone (2004) at T2. Sample items include: "I am good at resisting temptation" and "I have a hard time breaking bad habits." The Cronbach's alpha was 0.73 .

\subsubsection{Psychological detachment}

We used a subscale of the Recovery Experience Scale developed by Sonnentag and Fritz (2007) to assess employees' psychological detachment at T2. The psychological detachment scale 
contains 4 items, of which a sample item is "During after-work hours, I forget about work." The Cronbach's alpha coefficient was 0.82 .

\subsubsection{Unsafe behaviour}

We assessed coal miners' unsafe behaviour at T3. Unsafe behaviour was measured using 10 items, which were created for the purpose of this study in coordination with China's classification for casualty accidents of enterprise staff and workers. We followed the procedure of Stetzer and Hofmann (1996) to create the unsafe behaviour questionnaire. An example item is "In order to complete the task, I ignore the safety warning signs and safety operation signs."

We conducted an exploratory factor analysis with parallel analysis using MPLUS 7.0 to determine the structure of the unsafe behaviour questionnaire. As shown in Appendix 1, the result suggested that both the one-factor structure $\left(\chi^{2}=66.09, \mathrm{df}=35, \mathrm{RMSEA}=0.06, \mathrm{CFA}=0.93\right.$, $\mathrm{TLI}=0.91, \mathrm{SRMR}=0.04)$ and the two-factor structure $\left(\chi^{2}=49.85, \mathrm{df}=26, \mathrm{RMSEA}=0.06, \mathrm{CFA}=0.95\right.$, $\mathrm{TLI}=0.92, \mathrm{SRMR}=0.03)$ fit the date well. However, for the two-factor structure, nine items loaded on the first dimension, whereas only one item loaded on the second dimension. Furthermore, the two-factor structure is not significantly better than the one-factor structure $\left(\Delta \chi^{2}=16.19, \Delta \mathrm{df}=9\right.$, $\Delta \chi 2 / \Delta=1.79, n s)$. Therefore, we accepted the one-factor structure of unsafe behaviour in this study.

We present the items and factor loadings in Appendix 1. Additionally, we performed a confirmatory factor analysis (CFA) to test whether the one-factor model fit the data. The results suggested that the data fit this one-factor model reasonably well $\left(\chi^{2}=64.89, \mathrm{df}=35, \mathrm{RMSEA}=0.06\right.$, $\mathrm{CFI}=0.94, \mathrm{TLI}=0.92, \mathrm{SRMR}=0.04)$. The Cronbach's alpha for the overall scale was 0.85 .

\subsubsection{Control variables}

We used our participants' age, educational level, marital status, and organisational tenure as the control variables. Age and organisational tenure were measured in years. Education was 
measured using four continuous categories: primary school or below; middle school; vocational school; and college diploma or above. Marital status was a dummy variable coded as " $0=$ unmarried" and " 1 = married". Past research has shown that coal miners' age, marital status, and organisational tenure are associated with unsafe behaviour (De Witte,1999; Jermier, Gaines, \& McIntosh, 1989; Wei, Chen, \& Qi, 2015). Moreover, prior research shows that the overall education level of the workplace may influence its accident rate, that is, employees with lower educational levels are likely to have more workplace accidents than employees with higher educational levels (e.g., Choudhry \& Fang, 2008). Therefore, we controlled them to estimate the effect of job insecurity and the moderating effect of focal variables.

\section{Results}

\subsection{Confirmatory factor analyses}

Prior to hypotheses testing, we employed CFA procedures to assess the distinctiveness of the focal variables in our study: job insecurity, unsafe behaviour, self-control, and psychological detachment. We treated the second-order dimension of job insecurity as an indicator of its latent construct in the analyses. For the remaining three variables, we formed three parcels of items indicating each latent construct by averaging the items with the highest and lowest loadings respectively (Bagozzi \& Edwards, 1998). In doing so, we established a nested set of two alternative models to compare with the baseline four-factor model. Specifically, the alternative Model 1 is a three-factor model which sets psychological detachment and self-control to correlate at 1.0. The alternative Model 2 is a two-factor model which sets psychological detachment and self-control to correlate at 1.0, and job insecurity and unsafe behaviour to correlate at 1.0 as well. The results suggest that the baseline model fit the data well $\left(\chi^{2}=70.51, \mathrm{df}=38, \mathrm{RMSEA}=0.06, \mathrm{CFI}=0.97\right.$, $\mathrm{TLI}=0.96, \mathrm{SRMR}=0.04)$. Compared with Model $1\left(\chi^{2}=116.64, \mathrm{df}=39, \mathrm{RMSEA}=0.10, \mathrm{CFI}=0.94\right.$, 
$\mathrm{TLI}=0.91, \mathrm{SRMR}=0.16)$, and Model $2\left(\chi^{2}=324.74, \mathrm{df}=40, \mathrm{RMSEA}=0.18, \mathrm{CFI}=0.77, \mathrm{TLI}=0.69\right.$, $\mathrm{SRMR}=0.27)$, the four-factor model fit the data better than alternative models $\left(\Delta \chi^{2}=46.13\right.$ with $1 \mathrm{df}$ for alternative Model 1 and $\Delta \chi 2=254.23$ with $2 \mathrm{df}$ for alternative Model 2). Moreover, the result shows that all indicators' standardized loadings were significant at the .01 level. Thus, the results provided support for construct distinction.

\subsection{Descriptive statistics and correlations}

Table 1 illustrates the means, standard deviations, correlation coefficients, and reliability statistics for the variables. Job insecurity was positively correlated with unsafe behaviour $(r=.47, p<.01)$. Self-control was negatively correlated with job insecurity $(r=-.45, p<.01)$ and unsafe behaviour $(r=-.46, p<.01)$. Psychological detachment was negatively correlated with job insecurity $(r=-.40$, $p<.01)$ and unsafe behaviour $(r=-.38, p<.01)$.

[Insert Table 1 about here]

\subsection{Hypothesis testing}

Before testing the hypotheses, the independent variable and moderators were grand mean centred in order to reduce multicollinearity between the linear terms and their quadratic counterparts (Hofmann \& Gavin, 1998; Lam et al., 2015). Table 2 summarizes the results of hierarchical linear modelling, including the unstandardized beta coefficients, robust standard errors, and $\mathrm{R}^{2}$ change.

[Insert Table 2 about here]

Hypothesis 1 predicted that the relationship between job insecurity and unsafe behaviour is Ushaped. To test the hypothesis, we entered the control variables (i.e., married status, education level, age, and organisational tenure) and the linear term of job insecurity into Model 1, and then we entered job insecurity squared (the quadratic term of job insecurity) into Model 2. As shown in Table 2, the results of Model 2 indicated that the effect for the quadratic term of job insecurity on 
unsafe behaviour was positive and significant $(\beta=.76, S E=0.05, p<.01)$. To interpret the result, we plotted it on Figure 2. As depicted in Figure 2, job insecurity displays a moderate negative relationship with unsafe behaviour at low levels, but it increases to a significantly positive relationship at moderate-to-high levels (threshold/inflection point $=2.34$ ). Thus, Hypotheses 1 is supported.

\section{[Insert Figure 2 about here]}

Hypothesis 2 predicted that psychological detachment moderates the curvilinear relationship between job insecurity and unsafe behaviour. To test the hypothesis, we entered psychological detachment (Model 3), and interactions of psychological detachment with job insecurity and with job insecurity squared (Model 4). As shown in Table 2, the coefficient for the interaction term of psychological detachment with job insecurity squared was significant $(\beta=-.17, S E=.06, p<0.05)$. Hypothesis 2 is therefore supported.

Hypothesis 3 predicted that self-control moderates the curvilinear relationship between job insecurity and unsafe behaviour. To test the moderating effect, we entered self-control (Model 5), followed by the interactions of self-control with job insecurity and job insecurity squared (Model 4) into the hierarchical linear regression equations. As shown in Table 2, Model 6 suggests that the coefficient for the interaction term of self-control and job insecurity squared is not significant $(\beta=0.02, S E=.06, n s)$. Hypothesis 3 is therefore not supported.

We followed Preacher, Curran, and Bauer's (2006) recommendations to further test the simple slopes of the moderating effect. We first classified psychological detachment (i.e., the moderator) into the high group (+1 SD) and low group (-1 SD), and then tested the significance level of those simple slopes. Figure 3 presents the moderating effect of psychological detachment on the Ushaped relationship. A close examination of the simple slopes (in Table 3) reveals that at the low 
level of job insecurity, the slopes are insignificant for those with low psychological detachment $(\beta=-.14, S E=.15, n s)$ and for those high with psychological detachment $(\beta=.06, S E=.04, n s)$. At the medium level of job insecurity, the slope is positive and significant for those with low psychological detachment $(\beta=.83, S E=.06, p<0.01)$ and for those with high psychological detachment $(\beta=.65, S E=.08, p<0.01)$. At the high level of job insecurity, the slopes are both positive and significant for those with low psychological detachment $(\beta=1.82, S E=.12, p<0.01)$, and for those with high psychological detachment $(\beta=1.24, S E=.17, p<0.01)$.

[Insert Figure 3 and Table 3 about here]

\section{Discussion}

This study aimed to shed more light on the psychological mechanisms that influence the unsafe behaviours of coal miners. It found a curvilinear relationship between job insecurity and unsafe behaviour, and verified the moderating effect of psychological detachment, but not self-control, on this relationship. An empirical analysis of three-wave longitudinal data from 209 coal miners confirmed the U-shaped relationship. Furthermore, by verifying the moderating effect of psychological detachment, we found that coal miners with higher psychological detachment were less inclined to enact unsafe behaviours than their counterparts with lower psychological detachment. We also found that the moderating effect is more pronounced when levels of job insecurity range from moderate to high. However, we did not find evidence for the moderating effect of self-control on the U-shaped relationship. We present the detailed theoretical and practical implications in the following sections.

\subsection{Theoretical implications}

This study indicates that there is a non-linear association between job insecurity and unsafe behaviour, which provides a possible rationale for the inconsistent findings in previous studies. 
Our findings suggest that previous studies which reported a positive relationship between job insecurity and unsafe behaviour may have examined participants who were experiencing relatively moderate to high levels of job insecurity, and the studies which reported a negative relationship may have recruited participants who were experiencing relatively low to moderate levels of job insecurity. In addition, our result shows that the threshold/inception point of the U-shaped relationship is relatively small (smaller than the mean), and that the effect of very low job insecurity might be counterbalanced by a large number of participants with high job insecurity. As such, it is not surprising that most studies have reported a positive relationship between job insecurity and unsafe behaviour. Future research is needed to examine the effect of low job insecurity on unsafe behaviour, which will enrich our understandings of the psychological mechanisms leading to employees' unsafe behaviours.

Our study offers a theoretical interpretation of the curvilinear relationship between job insecurity and unsafe behaviour, thereby contributing to the literature on job insecurity. Past research on job insecurity generally indicates that job insecurity can escalate the tension between safety and productivity (e.g., Byrd, Gailey, Probst, \& Jiang, 2018). Caught between these competing demands, employees, according to COR theory, must decide how to allocate their finite resources to "optimize resource gain and prevent resource loss" (Byrd et al., 2018, p. 256). Our findings show that coal miners who experience high levels of job insecurity tend to prioritise productivity over safety in an attempt to retain their jobs while miners with low levels of job insecurity are less inclined to allocate their resources rationally. That is, low levels of job insecurity breed complacency and coal miners in this category are likely to work in a thoughtless, automated manner, wherein minimal concentration is given to safety compliance. A certain level of job insecurity can prompt miners to revert their attention back to safety compliance, resulting in a 
reduction in unsafe behaviour. Although previous studies have touched on the existence of such a negative relationship between job insecurity and unsafe behaviour (e.g., Parker et al., 2001; Probst, 2004), our study is the first to offer a rich explanation, drawing from COR theory, for why employees who feel extremely secure in their jobs might engage in more unsafe behaviours. By doing so, we offer a more complex and nuanced view on how employees respond to job insecurity and we provide an avenue for future research on other safety-related behaviours that arise in connection with job insecurity levels.

Although there has been significant research on the relationship between job insecurity and safety-related behaviours, the psychological mechanism that underpins this relationship has attracted less attention (Byrd et al., 2018). This study facilitates understandings of the mechanisms that explain the relationship by investigating the moderating role of psychological detachment and self-control. Both psychological detachment and self-control can lead to the ebb and flow of one's reservoir of personal resources (Rivkin, Diestel, \& Schmidt, 2014; Zijlstra, Cropley, \& Rydsted, 2014), which further influences how employees allocate their resources. The exertion of selfcontrol is consuming of one's personal resources (Hagger \& Martin, 2015; Lian, Yam, Ferris, \& Brown, 2017), whereas psychological detachment is a means for gaining or restoring these resources (Binnewies, Sonnentag, \& Mojza, 2010; Sonnentag \& Kühnel, 2016). Our results show that, between the two factors, psychological detachment is the more salient in moderating the curvilinear relationship between job insecurity and unsafe behaviour. High psychological detachment weakens the positive relationship between job insecurity and unsafe behaviour when job insecurity levels range from moderate to high, and it also diminishes the negative relationship when job insecurity levels are low. This finding supports the notion that employees benefit by having mental breaks from work (Bennett, Bakker, \& Field, 2017). 


\subsection{Practical implications}

Organisations should beware that very low levels of job insecurity can have adverse effects on safety-related behaviours of coal miners. Organisations have long focused on ways of reducing the unsafe behaviours of employees when they experience job insecurity, such as encouraging a more safety-oriented culture among employees (Byrd, et al., 2018; Jiang \& Probst, 2015). Organisations should also create a safety management system, and highlight the role of safety coordinators, which serve to keep employees vigilant and mindful of safe work practices, especially if employees are at risk of becoming complacent. Furthermore, organisations should design a reasonable workflow to facilitate the psychological detachment of coal miners, such as increasing the frequency of breaks each month ${ }^{1}$. In addition, organisations should consider providing training related to psychological detachment, which can enhance employees' awareness of strategies to mentally replenish themselves when they are away from work, such as refraining from job-related communications and engaging in meaningful activities during their leisure time.

\subsection{Limitations}

Despite these contributions, our study contains some limitations. First, even though our findings are in line with theoretical arguments about the presence of different psychological mechanisms at various levels of job insecurity, we did not directly measure these underlying mechanisms, such as complacency and the tension between productivity and safety compliance. Clearly, future research into the relationship between job insecurity and unsafe behaviour would be fruitful.

A second concern is our self-developed scale of unsafe behaviour. We had employed a rigorous procedure to develop the items, and we had examined the construct validity and reliability of our

\footnotetext{
${ }^{1}$ During the survey, we found that most participants chose to take monthly breaks of between one and two days.
} 
data. However, this scale was designed based on China's classification for casualty accidents of enterprise staff and workers, which may not be applicable for unsafe behaviour research in other countries.

A third limitation relates to the generalisability of our research findings. Many contextual factors may influence unsafe behaviours in coal miners, such as physical environment, leadership in safety matters, safety management, and group factors (Yu, Cao, Xie, Qu, \& Zhou, 2019). Future research should systematically investigate the effects of the contextual variables in our model to determine whether our findings are applicable to other contexts.

\section{Conclusion}

In this study, we proposed and tested a curvilinear relationship between job insecurity and unsafe behaviour in a sample of coal miners in northern China. We found that when levels of job insecurity ranged from low to moderate, coal miners exhibited less unsafe behaviours compared to when job insecurity levels were high, resulting in a U-shaped relationship. We also found that this curvilinear relationship could be moderated by psychological detachment but not by selfcontrol. That is, coal miners with higher degrees of psychological detachment were less inclined to engage in unsafe behaviours, compared with their counterparts with lower psychological detachment. Our findings suggest that organisations in the coal mining industry can benefit from carefully managing their employees' perceptions of job insecurity in order to discourage unsafe behaviours. 


\section{References}

Abildgaard, J. S., Nielsen, K., \& Sverke, M. (2017). Can job insecurity be managed? Evaluating an organizational-level intervention addressing the negative effects of restructuring. Work and Stress, 32, 105-123. https://doi.org/10.1080/02678373.2017.1367735.

Arstad, I., \& Aven, T. (2017). Managing major accident risk: Concerns about complacency and complexity in practice. Safety Science, 91, 114-121. https://doi.org/10.1016/j.ssci.2016.08.004.

Ashford, S. J., Lee, C., \& Bobko, P. (1989). Content, cause, and consequences of job insecurity: A theory-based measure and substantive test. Academy of Management Journal, 32, 803-829. http://dx.doi.org/10.2307/256569.

Bagozzi, R. P., \& Edwards, E. A. (1998). Goal setting and goal pursuit in the regulation of body weight. Psychology and Health, 13, 593-621. https://doi.org/10.1080/08870449808407421.

Van Horn, D. H. A. (1995). Losing control: How and why people fail at self-regulation. Clinical Psychology Review, 15, 367-368. https://doi.org/10.1016/0272-7358(95)90149-3.

Bennett, A. A., Bakker, A. B., \& Field, J. G. (2017). Recovery from work-related effort: A metaanalysis. Journal of Organizational Behavior, 39, 262-275. https://doi.org/10.1002/job.2217.

Binnewies, C., Sonnentag, S., \& Mojza, E. J. (2010). Recovery during the weekend and fluctuations in weekly job performance: A week-level study examining intra-individual relationships. Journal of Occupational and Organizational Psychology,83, 419-441. https://doi.org/10.1348/096317909X418049.

Brockner, J., Grover, S., Reed, T. F., \& Dewitt, R. L. (1992). Layoffs, job insecurity, and survivors' work effort: Evidence of an inverted-U relationship. Academy of Management Journal, 35, 413425. https://doi.org/10.5465/256380.

Burgard, S. A., Brand, J. E., \& House, J. S. (2009). Perceived job insecurity and worker health in 
the united states. Social Science \& Medicine, 69, 777-785. https://doi.org/10.1016/j.socscimed.2009.06.029.

Byrd, J., Gailey, N. J., Probst, T. M., \& Jiang, L. (2018). Explaining the job insecurity-safety link in the public transportation industry: The mediating role of safety-production conflict. Safety Science, 106, 255-262. https://doi.org/10.1016/j.ssci.2016.11.017.

Chan, D. (2009). So why ask me? Are self-report data really that bad? In C. E. Lance \& R. J. Vandenberg (Eds.), Statistical and methodological myths and urban legends: Doctrine, verity and fable in the organizational and social sciences (pp. 311-338). New York: Routledge.

Chi, N. W., Chang, H. T., \& Huang, H. L. (2015). Can personality traits and daily positive mood buffer the harmful effects of daily negative mood on task performance and service sabotage? A self-control perspective. Organizational Behavior \& Human Decision Processes, 131, 1-15. https://doi.org/10.1016/j.obhdp.2015.07.005.

Choudhry, R. M., \& Fang, D. (2008). Why operatives engage in unsafe work behavior: Investigating factors on construction sites. Safety Science, 46, 566-584. https://doi.org/10.1016/j.ssci.2007.06.027.

Christian, M. S., Bradley, J. C., Wallace, J. C., \& Burke, M. J. (2009). Workplace safety: A metaanalysis of the roles of person and situation factors. Journal of Applied Psychology, 94, 1103-1127. https://doi.org/10.1037/a0016172.

Costa, S., \& Neves, P. (2017). Job insecurity and work outcomes: the role of psychological contract breach and positive psychological capital. Work and Stress, 31, 375-394. https://doi.org/10.1080/02678373.2017.1330781.

Coway, J. M., \& Lance, C. E. (2010). What reviewers should expect from authors regarding common method bias in organizational research. Journal of Business and Psychology, 25, 325- 
334. https://doi.org/10.1007/s10869-010-9181-6.

De Ridder, D. T. D., Lensvelt-Mulders, G., Finkenauer, C., Stok, F. M., \& Baumeister, R. F. (2012). Taking stock of self-control: A meta-analysis of how trait self-control relates to a wide range of behaviors. Personality and Social Psychology Review, 16, 76-99. http://dx.doi.org/10.1177/1088868311418749.

De Witte, H. (1999). Job insecurity and psychological well-being. Review of the literature and exploration of some unresolved issues. European Journal of Work and Organizational Psychology, 8, 155-177. http://dx.doi.org/10.1080/135943299398302.

Denes-Raj, V., \& Epstein, S. (1994). Conflict between intuitive and rational processing: When people behave against their better judgment. Journal of Personality and Social Psychology, 66, 819-829. https://doi.org/10.1037//0022-3514.66.5.819.

Etzion, D., Eden, D., \& Lapidot, Y. (1998). Relief from job stress and burnout: Reserve service as a respite. Journal of Applied Psychology, 83, 577-585. http://dx.doi.org/10.1037/00219010.83.4.577.

Fiegenbaum, A., \& Thomas, H. (1988). Attitudes toward risk and the risk-return paradox: Prospect theory explanations. The Academy of Management Journal, 31, 85-106. http://dx.doi.org/10.2307/256499.

Foster, D. W., Young, C. M., \& Bärnighausen, T. W. (2014). Self-Control as a moderator of the relationship between drinking identity and alcohol use. Substance Use and Misuse, 49, 1340-1348. https://doi.org/10.3109/10826084.2014.901387.

Gino, F., Schweitzer, M. E., Mead, N. L., \& Ariely, D. (2011). Unable to resist temptation: How self-control depletion promotes unethical behavior. Organizational Behavior and Human Decision Processes, 115, 191-203. https://doi.org/10.1016/j.obhdp.2011.03.001. 
Hagger, \& Martin, S. (2015). Conservation of resources theory and the 'strength' model of selfcontrol: conceptual overlap and commonalities. Stress and Health, 31, 89-94. https://doi.org/10.1002/smi.2639.

Halbesleben, J. R. B., Neveu, J., Paustian-Underdahl, S. C., \& Westman, M. (2014). Getting to the "COR" understanding the role of resources in conservation of resources theory. Journal of Management, 40, 1334-1364. https://doi.org/10.1177/0149206314527130.

Hobfoll, S. E. (1989). Conservation of resources: A new attempt at conceptualizing stress. American Psychologist, 44, 513-524. http://dx.doi.org/10.1037/0003-066X.44.3.513.

Hobfoll, S. E., Halbesleben, J., Neveu, J., \& Westman, M. (2018). Conservation of Resources in the Organizational Context: The Reality of Resources and Their Consequences. Annual Review of Organizational Psychology and Organizational Behavior, 5, 103-128. https://doi.org/10.1146/annurev-orgpsych-032117-104640.

Hofmann, D. A., \& Gavin, M. B. (1998). Centering decisions in hierarchical linear models: Implications for research in organizations. Journal of Management, 24, 623-641. https://doi.org/10.1016/S0149-2063(99)80077-4.

Hyten, C., \& Ludwig, T. D. (2017). Complacency in process safety: A behavior analysis toward prevention strategies. Journal of Organizational Behavior Management, 37, 240-260. https://doi.org/10.1080/01608061.2017.1341860.

Janssens, M., Brett, J. M., \& Smith, F. J. (1995). Confirmatory cross-cultural research: Testing the viability of a corporation-wide safety policy. Academy of Management Journal, 38, 364-382. http://dx.doi.org/10.2307/256684.

Jermier, J. M., Gaines, J., \& McIntosh, N. J. (1989). Reactions to physically dangerous work: A conceptual and empirical analysis. Journal of Organizational Behavior, 10, 15-33. 
https://doi.org/10.1002/job.4030100103.

Jiang, L., \& Probst, T. M. (2015). The relationship between safety-production conflict and employee safety outcomes: Testing the impact of multiple organizational climates. Work and Stress, 29, 171-189. https://doi.org/10.1080/02678373.2015.1032384.

Kaplan, H. S., \& Gangestad, S. W. (2005). Life history theory and evolutionary psychology. In D. M. Buss (Ed.), The handbook of evolutionary psychology (pp. 69-95). Hoboken, NJ: Wiley. Kiazad K, Seibert SE, \& Kraimer ML. (2014). Psychological contract breach and employee innovation: a conservation of resources perspective. Journal of Occupational and Organizational Psychology, 87:535-56. https://doi.org/10.1111/joop.12062.

Kuhnel, J., Sonnentag, S., \& Bledow, R. (2012). Resources and time pressure as day-level antecedents of work engagement. Journal of Occupational and Organizational Psychology, 85, 181-198. https://doi.org/10.1111/j.2044-8325.2011.02022.x.

Lam, C. F., Liang, J., Ashford, S. J., \& Lee, C. (2015). Job insecurity and organizational citizenship behavior: Exploring curvilinear and moderated relationships. Journal of Applied Psychology, 100, 499-510. http://dx.doi.org/10.1037/a0038659.

Lenné, Michael G., Salmon, P. M., Liu, C. C., \& Trotter, M. (2012). A systems approach to accident causation in mining: An application of the hfacs method. Accident Analysis \& Prevention, 48, 111117. https://doi.org/10.1016/j.aap.2011.05.026.

Li, H., Lu, M., Hsu, S. C., Gray, M., \& Huang, T. (2015). Proactive behavior-based safety management for construction safety improvement. Safety Science, 75, 107-117. https://doi.org/10.1016/j.ssci.2015.01.013.

Lian, H., Yam, K. C., Ferris, D. L., \& Brown, D. (2017). Self-control at work. Academy of Management Annals, 11, 703-732. https://doi.org/10.5465/annals.2015.0126. 
Masia, U., \& Pienaar, J. (2011). Unravelling safety compliance in the mining industry: Examining the role of work stress, job insecurity, satisfaction and commitment as antecedents. SA Journal of Industrial Psychology, 37, 01-10. http://dx.doi.org/10.1402/sajip.v37i1.937.

Moray, N., \& Inagaki, T. (2010). Attention and complacency. Theoretical Issues in Ergonomics Science, 1, 354-365. https://doi.org/10.1080/14639220052399159.

Muraven, M., Shmueli, D., \& Burkley, E. (2006). Conserving self-control strength. Journal of Personality and Social Psychology, 91, 524-537. https://doi.org/10.1037/0022-3514.91.3.524.

Muraven, M., Tice, D. M., \& Baumeister, R. F. (1998). Self-control as a limited resource: Regulatory depletion patterns. Journal of Personality and Social Psychology, 74, 774-789. http://dx.doi.org/10.1037/0022-3514.74.3.774.

Parker, S. K., Axtell, C. M., \& Turner, N. (2001). Designing a safer workplace: Importance of job autonomy, communication quality, and supportive supervisors. Journal of Occupational Health Psychology, 6, 211-228. http://doi.apa.org/getdoi.cfm?doi=10.1037/1076-8998.6.3.211.

Paul, P. S., \& Maiti, J. (2007). The role of behavioral factors on safety management in underground mines. Safety Science, 45, 449-471. https://doi.org/10.1016/j.ssci.2006.07.006.

Podsakoff, P. M., Mackenzie, S. B., Lee, J. Y., \& Podsakoff, N. P. (2003). Common method biases in behavioral research: A critical review of the literature and recommended remedies. Journal of Applied Psychology, 88, 879-903. http://dx.doi.org/10.1037/0021-9010.88.5.879.

Preacher, K. J., Curran, P. J., \& Bauer, D. J. (2006). Computational tools for probing interactions in multiple linear regression, multilevel modeling, and latent curve analysis. Journal of Educational \& Behavioral Statistics, 31, 437-448. https://doi.org/10.3102/10769986031004437.

Probst, T. M. (2004). Safety and Insecurity: Exploring the Moderating Effect of Organizational Safety Climate. Journal of Occupational Health Psychology, 9, 3-10. 
https://doi.org/10.1037/1076-8998.9.1.3.

Probst, T. M., \& Brubaker, T. L. (2007). Organizational safety climate and supervisory layoff decisions: preferences versus predictions. Journal of Applied Social Psychology, 37,1630-1648. https://doi.org/10.1111/j.1559-1816.2007.00230.x.

Probst, T. M., Brubaker, T. L., \& Barsotti, A. (2008). Organizational injury rate underreporting: The moderating effect of organizational safety climate. Journal of Applied Psychology, 93, 11471154. https://doi.org/10.1037/0021-9010.93.5.1147.

Probst, T. M., Petitta, L., Barbaranelli, C., \& Lavaysse, L. M. (2018). Moderating effects of contingent work on the relationship between job insecurity and employee safety. Safety Science, 106, 285-293. https://doi.org/10.1016/j.ssci.2016.08.008.

Richter, A., \& Näswall, K. (2018). Job insecurity and trust: Uncovering a mechanism linking job insecurity to well-being. Work \& Stress, 33, 22-40. https://doi.org/10.1080/02678373.2018.1461709.

Rivkin, W., Diestel, S., \& Schmidt, K. (2014). Psychological detachment: A moderator in the relationship of self-control demands and job strain. European Journal of Work and Organizational Psychology, 24, 376-388. https://doi.org/10.1080/1359432X.2014.924926.

Ruderman, M. N., Ohlou, P. J. Panzer, K., \& King. S. N. (2002). Benefit of multiple roles for managerial women. Academy of Management Journal. 45. 369- 386. http://dx.doi.org/10.2307/3069352.

Shallice, T., \& Burgess, P. (1993). Supervisory control of action and thought selection. In A. Baddeley \& L. Weiskrantz (Eds.), Attention: Selection, awareness, \& control (pp. 171-187). Oxford, England: Oxford University.

Shoss, M. K. (2017). Job Insecurity: An Integrative Review and Agenda for Future Research. 
Journal of Management, 43, 1911-1939. http://dx.doi.org/10.1177/0149206317691574.

Slappendel, C., Laird, I., Kawachi, I., Marshall, S., \& Cryer, C. (1993). Factors affecting workrelated injury among forestry workers: A review. Journal of Safety Research, 24, 19-32. https://doi.org/10.1016/0022-4375(93)90048-R.

Sonnentag, S., \& Bayer, U. V. (2005). Switching off mentally: Predictors and consequences of psychological detachment from work during off-job time. Journal of Occupational Health Psychology, 10, 393-414. https://doi.org/10.1037/1076-8998.10.4.393.

Sonnentag, S., \& Binnewies, C. (2013). Daily affect spillover from work to home: Detachment from work and sleep as moderators. Journal of Vocational Behavior, 83, 198-208. https://doi.org/10.1016/j.jvb.2013.03.008.

Sonnentag, S., Binnewies, C., \& Mojza, E. J. (2010). Staying well and engaged when demands are high: The role of psychological detachment. Journal of Applied Psychology, 95, 965-976. https://doi.org/10.1037/a0020032.

Sonnentag, S., \& Fritz, C. (2007). The recovery experience questionnaire: Development and validation of a measure for assessing recuperation and unwinding from work. Journal of Occupational Health Psychology, 12, 204. https://doi.org/10.1037/1076-8998.12.3.204.

Sonnentag, S., \& Fritz, C. (2015). Recovery from job stress: The stressor-detachment model as an integrative framework. Journal of Organizational Behavior, 36, S72-S103. https://doi.org/10.1002/job.1924.

Sonnentag, S., \& Kühnel, J. (2016). Coming back to work in the morning: Psychological detachment and reattachment as predictors of work engagement. Journal of Occupational Health Psychology, 21, 379-390. https://doi.org/10.1037/ocp0000020.

Stetzer, A., \& Hofmann, D. A. (1996). Risk compensation: Implications for safety interventions. 
Organizational Behavior \& Human Decision Processes, 66, 73-88. https://doi.org/10.1006/obhd.1996.0039.

Sverke, M., De Witte, H., Näswall, K., \& Hellgren, J. (2010). European perspectives on job insecurity: Editorial introduction. Economic and Industrial Democracy, 31, 175-178. https://doi.org/10.1177/0143831X10365601.

Tangney, J. P., Baumeister, R. F., \& Boone, A. L. (2004). High self - control predicts good adjustment, less pathology, better grades, and interpersonal success. Journal of Personality, 72 , 271-324. https://doi.org/10.1111/j.0022-3506.2004.00263.x.

Warm, J. S., Matthews, G., \& Finomore Jr, V. S. (2018). Vigilance, workload, and stress. P. A. Hancock \& J. L. Szalma (Eds.), In Performance under stress (pp.131-158). London: Routledge Publishing.

Wei, J., Chen, H., \& Qi, H. (2015). Who reports low safety commitment levels? an investigation based on Chinese coal miners. Safety Science, $80, \quad 178$ 188.https://doi.org/10.1016/j.ssci.2015.07.024.

Yu, K., Cao, Q., Xie, C., Qu, N., Zhou, \& L. (2019). Analysis of intervention strategies for coal miners' unsafe behaviors based on analytic network process and system dynamics. Safety Science, 118, 145-157. https://doi.org/10.1016/j.ssci.2019.05.002.

Zhang, S., Shi, X., \& Wu, C. (2017). Measuring the effects of external factor on leadership safety behavior: Case study of mine enterprises in China. Safety Science, 93, 241-255. https://doi.org/10.1016/j.ssci.2016.12.017.

Zijlstra, F. R. H., Cropley, M., \& Rydstedt, L. W. (2014). From recovery to regulation: An attempt to reconceptualize 'recovery from work'. Stress and Health, 30, 244-252. https://doi.org/10.1002/smi.2604 


\section{Table 1}

Means, standard deviations, and correlations among study variables

\begin{tabular}{|c|c|c|c|c|c|c|c|c|c|c|}
\hline Variable & Mean & SD & 1 & 2 & 3 & 4 & 5 & 6 & 7 & 8 \\
\hline 1. Marital status & 1.51 & 0.32 & - & & & & & & & \\
\hline 2. Age & 26.7 & 3.90 & -.02 & - & & & & & & \\
\hline 3. Organisational tenure & 6.71 & 4.02 & .08 & $.44^{* *}$ & - & & & & & \\
\hline 4. Education & 2.82 & 0.97 & $-.17^{*}$ & -.09 & $-.21^{*}$ & - & & & & \\
\hline 5. Job insecurity & 3.18 & 0.80 & -.09 & $.17^{*}$ & .10 & $-.25^{* *}$ & $(.85)$ & & & \\
\hline 6. Self-control & 3.05 & 0.78 & .07 & -.13 & -.06 & $.28^{* *}$ & $-.45 * *$ & $(.73)$ & & \\
\hline 7. Psychological detachment & 2.70 & 0.73 & $.19^{* *}$ & -.05 & -.04 & $.15^{*}$ & $-.40^{* *}$ & $.32^{* *}$ & $(.82)$ & \\
\hline 8. Unsafe behaviour & 2.95 & 0.72 & -.03 & $.22^{* *}$ & .13 & $-.31^{*}$ & $.47^{* *}$ & $-.46^{* *}$ & $-38^{* *}$ & $(.83)$ \\
\hline
\end{tabular}

Note. $N=209 . \mathrm{SD}=$ standard deviations. Reliability coefficients are reported along the diagonal. ${ }^{*} p<.05,{ }^{* *}$ $p<.01,{ }^{* * *} p<.001$. 
Table 2

Results of Multiple Linear Modeling Analyses with Unsafe Behaviour

\begin{tabular}{|c|c|c|c|c|c|c|}
\hline \multirow[b]{2}{*}{ Predictor variable } & \multicolumn{6}{|c|}{ Unsafe behaviour } \\
\hline & Model 1 & Model 2 & Model 3 & Model 4 & Model 5 & Model 6 \\
\hline Intercept & $.13(.18)$ & $.15(.20)$ & $01(.19)$ & $.06(.19)$ & $.02(.19)$ & $.04(.18)$ \\
\hline Marital status & $.02(.09)$ & $-.05(.07)$ & $-.01(.07)$ & $.03(.07)$ & $-.02(.06)$ & $-.04(.06)$ \\
\hline Age & $.19(.10)$ & $-.01(.08)$ & $.01(.08)$ & $-.01(.08)$ & $-.01(.08)$ & $-.01(.08)$ \\
\hline Organisational tenure & $-.01(.04)$ & $-.01(.03)$ & $.01(.03)$ & $.02(.03)$ & $.01(.03)$ & $.01(.02)$ \\
\hline Education & $-.13^{* *}(.04)$ & $-.14^{* * *}(.03)$ & $-.12^{* *}(.03)$ & $-.15^{* * *}(.03)$ & $-.10^{* *}(.03)$ & $\begin{array}{c}-.12^{* * *} \\
(.03)\end{array}$ \\
\hline Job insecurity & $.76^{* * *}(.05)$ & $.88^{* * *}(.04)$ & $.81^{* * *}(.05)$ & $.74^{* * *}(.05)$ & $.75^{* * *}(.05)$ & $\begin{array}{l}.76^{* * *} \\
(.05)\end{array}$ \\
\hline Job insecurity squared & & $.53^{* * *}(.04)$ & $.51^{* * *}(.04)$ & $.49^{* * *}(.05)$ & $.48^{* * *}(.04)$ & $.41^{* * * *}(.05)$ \\
\hline Self-control & & & & & $-.26^{* * *}(.05)$ & $-.16^{*}(.06)$ \\
\hline Psychological detachment & & & $-.20^{* *}(.05)$ & $-.09(.06)$ & & \\
\hline Job insecurity $\times$ Self-control & & & & & & $\begin{array}{l}-.25^{* * *} \\
(.07)\end{array}$ \\
\hline $\begin{array}{l}\text { Job insecurity } \times \text { Psychological } \\
\text { detachment }\end{array}$ & & & & $-.12(.07)$ & & \\
\hline $\begin{array}{l}\text { Job insecurity squared } \times \text { Self- } \\
\text { control }\end{array}$ & & & & & & $.02(.06)$ \\
\hline $\begin{array}{l}\text { Job insecurity squared } \times \\
\text { Psychological detachment }\end{array}$ & & & & $-.17^{* *}(.06)$ & & \\
\hline$R^{2}$ & .53 & .70 & .73 & .74 & .74 & .75 \\
\hline$\Delta R^{2}$ & & $.17^{* * *}$ & $.02^{* *}$ & $.01^{*}$ & $.04^{* * *}$ & $.01^{* *}$ \\
\hline$F$ & $46.07^{* * *}$ & $82.04^{* * *}$ & $77.50^{* * *}$ & $63.49^{* * *}$ & $82.42^{* * *}$ & $69.09^{* * *}$ \\
\hline
\end{tabular}

Note. $N=209$. Unstandardized regression coefficients are reported. ${ }^{*} p<.05,{ }^{* *} p<.01,{ }^{* * *} p<.001$. For marital status, $0=$ unmarried, $1=$ married. For education, 0 = primary school or below, $2=$ middle school, $3=$ vocational school, $4=$ college diploma or above. Beta coefficients were presented, and the corresponding standard errors were reported in the parentheses. 
Table 3

Results of simple slopes analysis.

\begin{tabular}{|c|c|c|c|c|c|c|}
\hline Interaction & $\begin{array}{l}\text { Independent } \\
\text { variable }\end{array}$ & Moderator condition & $\beta$ & $S E$ & $t$ & $95 \% C I$ \\
\hline \multirow{6}{*}{$\begin{array}{l}\text { Job insecurity squared } \times \\
\text { psychological } \\
\text { detachment }\end{array}$} & low level of job & Low PD & -.14 & .15 & -.93 & {$[-.46, .16]$} \\
\hline & insecurity & High PD & .06 & .04 & 1.35 & {$[-.02, .15]$} \\
\hline & medium level of & Low PD & .83 & .06 & 12.93 & {$[.71, .96]$} \\
\hline & job insecurity & High PD & .65 & .08 & 7.74 & {$[.48, .81]$} \\
\hline & high level of job & Low PD & 1.82 & .12 & 14.15 & {$[1.57,2.07]$} \\
\hline & insecurity & High PD & 1.24 & .17 & 7.08 & {$[.89,1.58]$} \\
\hline
\end{tabular}

Note. $N=209 .{ }^{*} p<0.05 . C I=$ Confidence Interval, $P D=$ Psychological Detachment.

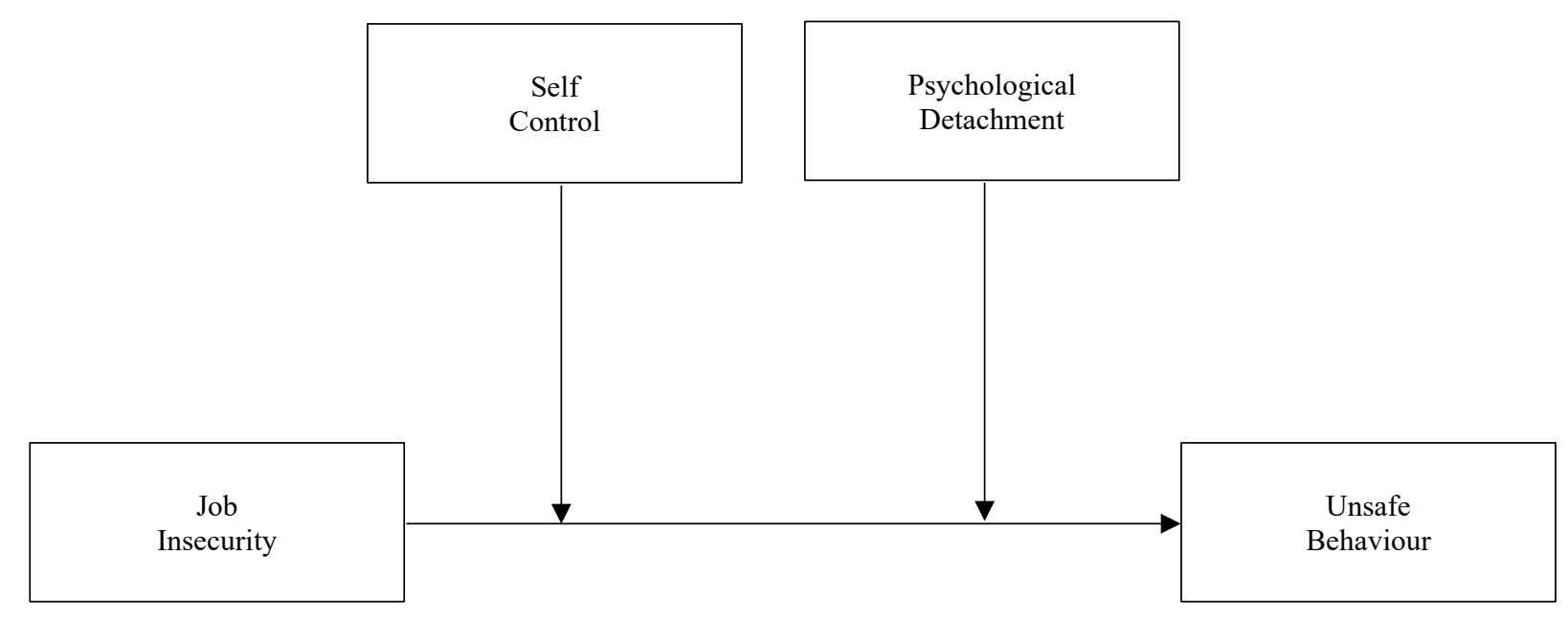

Figure 1. Conceptual model of the study 


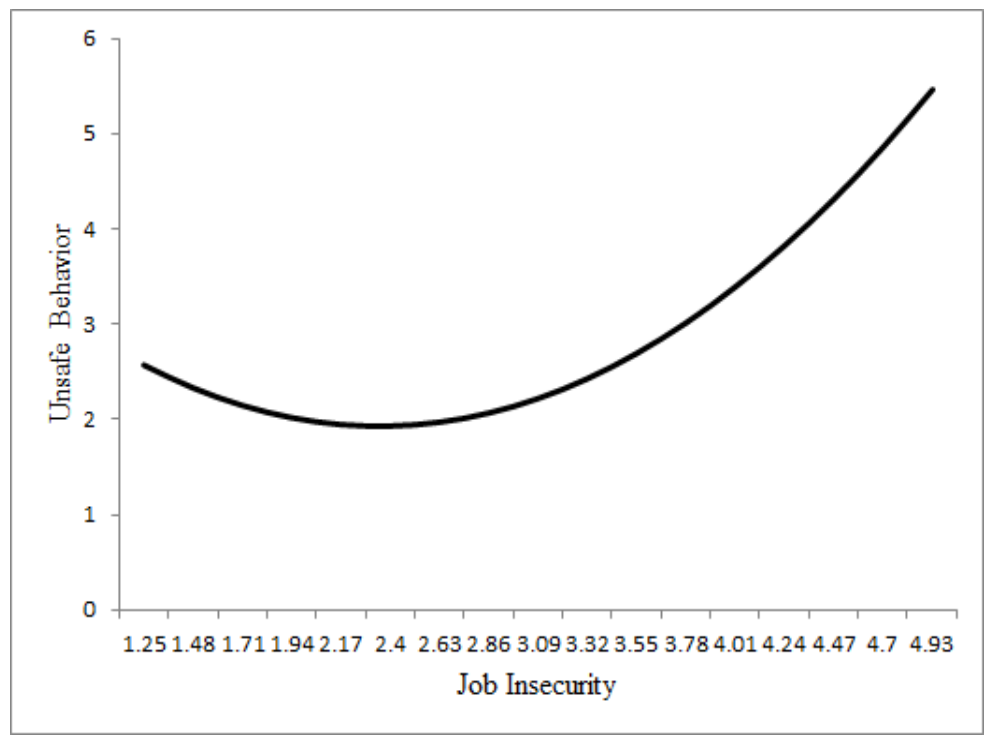

Figure 2. The curvilinear relationship between job insecurity and unsafe behaviour

Interaction Plots at Various Levels of the

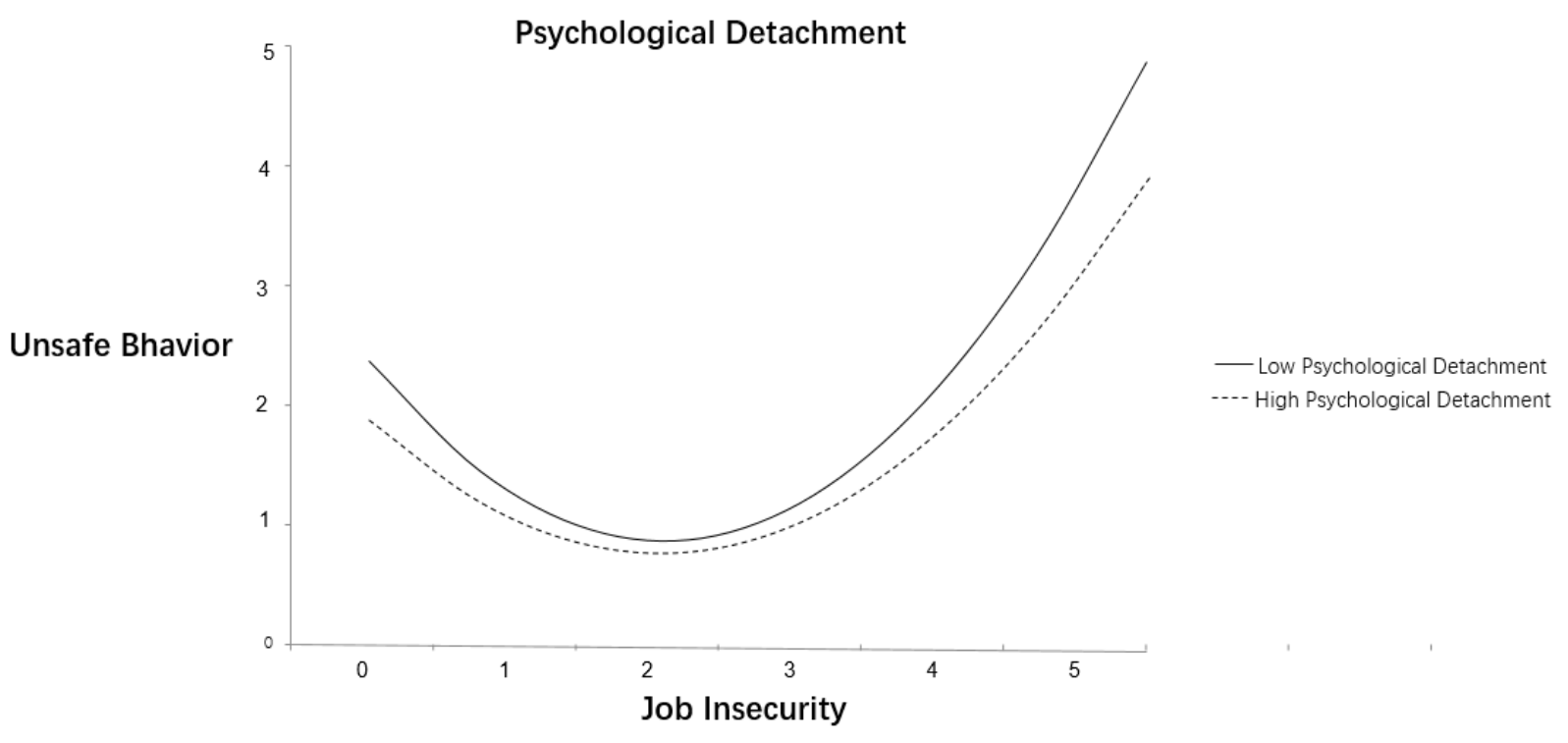

Figure 3. Interaction effects of job insecurity and psychological detachment

on unsafe behaviour 
Appendix: Factor loadings of one-factor structure and two-factor structure of unsafe behaviour questionnaire

\begin{tabular}{|c|c|c|c|}
\hline \multirow{2}{*}{ item } & \multirow{2}{*}{ One-factor structure } & \multicolumn{2}{|c|}{ Two-factor structure } \\
\hline & & the first factor & the second factor \\
\hline 1.In order to complete my task, I ignore the safety rules and security signs at work. & $.55^{*}$ & $.67^{*}$ & -.18 \\
\hline 2. I maintain and repair equipment according to my own habits. & $.48^{*}$ & $.48^{*}$ & .01 \\
\hline 3. When my workload is too heavy, I tend to take shortcuts. & $.63^{*}$ & $.63^{*}$ & -.03 \\
\hline $\begin{array}{l}\text { 4. For convenience of operation, I replace safe mechanical equipment with some unsafe } \\
\text { mechanical equipment. }\end{array}$ & $.47^{*}$ & .24 & .43 \\
\hline $\begin{array}{l}\text { 5. During production, my operation relies on my work experience rather than safety } \\
\text { regulations. }\end{array}$ & $.35^{*}$ & -.01 & $.59^{*}$ \\
\hline $\begin{array}{l}\text { 6. In order to accomplish the task quickly, I take unmanned transportation in violation of } \\
\text { safety regulations. }\end{array}$ & $.69^{*}$ & $.61^{*}$ & .15 \\
\hline $\begin{array}{l}\text { 7. Although wearing personal protective equipment is mandatory, I tend not to follow the } \\
\text { rule. }\end{array}$ & $.38^{*}$ & $.37^{*}$ & .01 \\
\hline $\begin{array}{l}\text { 8. In order to save time, I ignore the safe operating procedure and carry out operation while } \\
\text { the machine is running. }\end{array}$ & $.69^{*}$ & $.75^{*}$ & -.09 \\
\hline $\begin{array}{l}\text { 9. I pretend to understand the operational procedures, which causes me to neglect potential } \\
\text { safety hazards. }\end{array}$ & $.78^{*}$ & $.77^{*}$ & .03 \\
\hline 10. I do not check working environment before entering hazardous areas. & $.46^{*}$ & .29 & .31 \\
\hline
\end{tabular}

Note. $N=209 .{ }^{*} p<0.05$. 